\title{
Recording patients' views on organ donation: when to ask them and how to record the answer
}

\author{
Hany N Riad, Richard A Banks
}

Transplant Unit, Royal Devon and Exeter Hospital (Wonford), Exeter EX2 5DW

Hany N Riad, FRCS, associate specialist

Gloucestershire Royal Hospital, Gloucester GL1 3NN

Richard A Banks, MD, consultant physician and nephrologist

Correspondence to: Dr Banks.

BrMed f 1990;301:155
Renal transplantation is the treatment of choice for end stage kidney failure. ${ }^{1-3}$ Similarly, the effectiveness of transplantation of the heart, lung, liver, and cornea is well established. The waiting list for kidney transplantation, however, increases every year and with it the burden of dialysis on both the NHS and the patient.

Recording of a person's wish to donate organs is haphazard. In the United Kingdom reliance is placed on "opting in" organ donor cards, but these are unreliable and usually not available at the time of death. One alternative is to record people's wishes on computer. In this study we determined whether patients were happy to be asked about organ donation, under what circumstances they would prefer to be approached, and how they would choose to have the information recorded.

\section{Subjects, methods, and results}

We asked every consultant in two district general hospitals for their consent for a questionnaire to be handed to all adult outpatients at their first appointment over two months. Clinics comprised those in general medicine; general surgery; ear, nose, and throat surgery; ophthalmology; and dermatology. Altogether $78(94 \%)$ consultants consented, and 723 questionnaires were analysed.

The first question asked whether the patient would object to being asked his or her views on donating organs. Of the 723 patients given a questionnaire, 34 either stated that they would object to being asked about donation or refused to complete the questionnaire and 63 did not complete the questionnaire but were indifferent to the issue. The remaining 626 had no objections and were then asked to select which of three times they would prefer to be asked about organ donation. Of the 451 patients who expressed a preference, 246 chose their first outpatient visit, 117 chose discharge from hospital, and 88 chose admission to hospital. In the final question the same 626 patients were asked to register approval or disapproval of several alternative methods of recording their wish: 492 approved of the present donor card system, 477 were happy with a record being kept in the hospital notes, and 433 approved of records being stored on a computer. Only 94 were happy with the idea of an "opting out" donor card stating that they did not want to become an organ donor when they died.

\section{Comment}

Approaching distressed relatives at the time of death to ask about organ donation is extremely difficult and was the most important factor restricting harvesting of organs in a recent survey. ${ }^{4}$ Even when relatives are approached $30 \%$ do not give permission. ${ }^{5}$ Undoubtedly, the knowledge that a relative had wanted to become an organ donor would be an enormous comfort to the bereaved and ease the task of approaching them. We believe that this would increase the numbers of relatives consenting to donation of organs.

We believe that it would be sensible and practical to record patients' views on organ donation when they attend hospital for fairly minor reasons. If our survey is representative few consultants would object to their patients being approached and $87 \%$ of the patients would be happy to register their views. There was little objection to using a computer to store the information. We found that patients would prefer to be questioned in the outpatient department, and perhaps this would be easier than at the discharge of an inpatient.

In Exeter two thirds of donors have attended an outpatient department at least once in their lifetime. Every year over 50000 adults attend the two hospitals as new outpatients. The vast majority come from a fairly stable local population. If they were asked to register their views on organ donation a large record of people who had given permission for organs to be removed after death could be built up fairly quickly. A recent questionnaire from the British Kidney Patients' Association showed that though $71 \%$ of the population are in favour of organ donation, only $23 \%$ carry donor cards. If the increasing gap between supply and demand for organ transplantation is to be met alternative methods of approaching the public are clearly necessary. We suggest that a question on organ donation be included in the registration form for new outpatients and that the information be recorded on the hospital computer under the provisions of the Data Protection Act.

\section{Wood IT, Mallick NP, Wing AJ. Prediction of resources needed to achieve the national target for treatment of renal failure. Br Med $\mathcal{F}$ 1987;294:1467-70. \\ 2 Ehrich JHH, Rizzoni G, Broyer M, et al. Combined report on regular dialysis and transplantation of children in Europe, 1987. Proceedings of the European and transplantation of children in Europe, 1987. \\ 3 Brunner FP, Fassbinder W, Broyer M, et al. Combined report on regular dialysis and transplantation in Europe, XVIII, 1987. Proceedings of the European Dialysis and Transplant Association 1988:25:14-6. \\ 4 Wakeford RE, Stepney R. Obstacles to organ donation. Br f Surg 1989;76: 435-9. \\ 5 Gore $\mathrm{SM}$, Hinds $\mathrm{CJ}$, Rutherford AJ. Organ donation from intensive care unit in Britain. Br Med f 1989;299:1193-7.}

(Accepted 23 April 1990)

\section{ONE HUNDRED YEARS AGO}

For many years we have been familiar with the allegations of antivaccinators as to injuries which are said to have resulted from vaccination. One of the most absurd is that vaccination is the cause of blindness. A few weeks ago the Principal of the Royal Normal College for the Blind at Upper Norwood was summoned before the Croydon Borough Bench in respect of the non-vaccination of his child. In answer to the proceedings relating to this matter, he justified his non-compliance with the vaccination law by pleading that it was due to his knowledge of so many cases in the College in which blindness had resulted from vaccination. This was rightly deemed to be a statement of sufficient importance to warrant an inquiry by the College Committee of Management. The investigation which the Committee caused to be made by their medical officer, Dr. Hetley, shows that out of the 140 pupils in the Institution eight attributed their blindness to vaccination, but that seven out of the eight were conclusively proved to owe their blindness to other causes than vaccination, while in the eighth case there was, in the opinion of the local medical officer and of $\mathrm{Mr}$. Hulke, no reason whatever for believing that the assertions of a violent antivaccinationist were really trustworthy. The inquiry incidentally showed that two children in the College are marked with small-pox. One of them shows no signs of vaccination, and the other has admittedly not been vaccinated. In both these cases the loss of sight has been entirely due to small-pox. We think that the Committee of the Royal Normal College has done well to institute this inquiry. The opposition to vaccination is chiefly based on the unfounded statements of anti-vaccinators, and the best way of counteracting it is by instituting inquiries by competent and impartial persons, in every case in which injury is alleged, on apparently good authority, to have resulted from vaccination. The process is tedious, and many would think unnecessary, but in the present state of public opinion with regard to vaccination, we think such a course is, on the whole, to be recommended. (British Medical fournal 1890;i:614) 